\title{
DA UNIÃO À FORTALEZA OU COMO A RELAÇÃO DE DEPEN- DÊNCIA ENTRE MIGRAÇÃO E INTEGRAÇÃO PODEM FAZER DESAPARECER A IDEIA DE UNIÃO EUROPEIA
}

\author{
FROM UNION TO FORTRESS OR HOW THE RELATION OF DE- \\ PENDENCE BETWEEN MIGRATION AND INTEGRATION CAN \\ PROVOQUE THE ABOLITION OF EUROPEAN UNION IDEALS
}

\author{
Paulo Potiara de Alcântara Veloso"
}

\begin{abstract}
RESUMO
O presente artigo procura analisar as correlações entre a migração e processos de integração econômica, principalmente a União Europeia, buscando verificar a validade da hipótese de trabalho que se fundamenta na existência de uma insuperável dependência entre ambos os fenômenos, pois são resultados do mesmo processo social de globalização. O caminho metodológico percorre as definições de fronteiras, dentro da lógica hermenêutica do direito internacional econômico, e sua relação com o processo de globalização econômica, demonstrando que a migração é um poderoso mecanismo de redefinição de fronteiras geográficas e não geográficas, além de ser também a base de legitimação de movimentos políticos eurocéticos. Ao final, conclui que migração e integração são fenômenos originados do mesmo processo de globalização e lutar contra um é lutar contra o outro e consequentemente é também lutar contra o direito internacional econômico e principalmente, contra um processo de globalização profundo que está reposicionando as sociedades humanas.
\end{abstract}

PALAVRAS-CHAVE: Migração. Direito Internacional Econômico. União Europeia.

\begin{abstract}
The present article analyzes the correlation between migration and economic integration processes, especially the European Union, in order to verify the validity of the working hypothesis that can be summarized as: migration and integration are profoundly dependent phenomena and the existence of one is the condition for the existence of the other. The methodological path has the hermeneutical lenses of international economic law as its main interpretation tool. The discussion goes from boundaries definition and its relation with the process of economic globalization, demonstrating that migration is a powerful mechanism for redefining geographical and non-geographical borders, as well as being the base of legitimacy of Eurosceptic political movements. In the end, it concludes that migration and integration are phenomena originated from the same process of globalization and fighting the former is a fight against the later and consequently is also fighting international economic law and the process of globalization.
\end{abstract}

KEYWORDS: Migration. International Economic Law. European Union.

\section{INTRODUÇÃO}

Migração é uma palavra, que acompanhada da expressão "União Europeia” possivelmente evoca no leitor a noção de crise, conceito este que pode acompanhar indistintamente qualquer um dos dois fenômenos acima. Talvez

\footnotetext{
* Professor do Programa de Mestrado em Direito da Universidade Comunitária da Região de Chapecó - UNOCHAPECÓ e professor da Faculdade Cesusc. Coordenador do Núcleo de Pesquisa em Direito Internacional NDInter - CESUSC/CNPq. Doutor em Direito pela Universidade Federal de Santa Catarina.E-mail: paulo.potiara@cesusc.edu.br.
} 
apenas este fato seja indicação inicial suficiente para sustentar a hipótese deste trabalho, que se põe nos seguintes termos: migração e integração são fenômenos intrinsecamente dependentes e a existência de ambos é uma consequência de um fenômeno social profundo denominado globalização.

A partir desse processo de globalização, optou-se por verificar quais os efeitos dos fenômenos migratório contemporâneos sobre as fronteiras e sua definição, principalmente dentro da União Europeia, que vem sendo um dos principais destinos de migrantes internacionais.

Dessa forma, aproximando a migração da lente de análise do presente artigo, o primeiro tópico trabalha sobre a relação entre aquele conceito e o direito internacional econômico, fundando suas aproximações em torno da relevância que o conceito de fronteira possui para ambos os instrumentais analíticos. No item subsequente insere-se o conceito de integração econômica e formação de blocos de integração, principalmente a União Europeia, dentro da discussão, o que se dá também pela aproximação entre os conceitos de integração, fronteiras e direito internacional econômico.

Como último item de análise, parte-se para a correlação entre todos os elementos desse instrumental analítico, momento em que se procura definir os contornos de validade (ou invalidade) da hipótese apresentada.

Por fim, conclui-se pela validade da hipótese de trabalho, verificando-se que há uma forte interligação entre os dois conceitos basilares da análise aqui proposta, principalmente quando observados a partir da lente conceitual do direito internacional público. Tanto migração como integração podem ser entendidas como consequências típicas do processo de globalização econômica atual e o primeiro fenômeno tem sido determinante para a sustentação ou dissolução do ideal integracionista europeu. Mas isso se dá não como consequência prática do processo migracional em si, mas sim como reflexo da percepção desse processo migracional sobre a população europeia, o que acaba abrindo margem para discursos políticos eurocéticos.

\section{MIGRAÇÃO E DIREITO INTERNACIONAL ECONÔMICO?}

Antes de nos dedicarmos à análise da migração tomada a partir das lentes hermenêuticas do direito internacional econômico, optamos por iniciar o debate a partir de uma afirmação aparentemente simplista, generalista e, sem dúvida alguma, bastante óbvia, qual seja: a migração é um fenômeno social complexo. E por que adotamos esta opção? A resposta reside principalmente no fato que a relação entre migração e mudanças sociais profundas, além de demonstrar uma falsa simplicidade e esconder a em si alguns relevantes elementos de definição, traz também em seu bojo, a relação mais íntima entre o fenômeno migracional e aquele do direito internacional econômico.

As percepções que nascem diretamente a partir dessa relação entre migração e complexidade determina importantes perspectivas que ajudam a esboçar 
de maneira mais plausível e crítica os fundamentos do fenômeno, principalmente em relação à amplificada rede de conhecimentos equivocados e parciais construídos pela política contemporânea, principalmente a partir do início da “crise" migracional vivenciada pela Europa. Dentre essas perspectivas - ou elementos de definição - uma das mais relevantes é representada pela possibilidade de rompermos com a ideia da praxis rasteira que comumente acompanha os posicionamentos políticos e jurídicos acerca do tema migração. Como qualquer fenômeno complexo, raramente pode ser explicado por meio de respostas fáceis, pois a migração está enraizada em mecanismos sociais muito mais profundos do que meramente o "fluxo geográfico de seres humanos ansiosos por melhores condições de vida”, como pode nos fazer pensar o discurso político de ocasião. Outras perspectivas implicam também em, por exemplo, desmistificar a percepção minimalista que define a migração enquanto agente causador de uma profunda crise europeia, pois a relação não pode ser estabelecida em tão tênues relações de causa e efeito. A migração e também a crise europeia são decorrências de mudanças sociais mais profundas, que se capilarizam a partir de elementos políticos, econômicos, estratégicos, tecnológicos, culturais, sociais, ambientais, etc., e ambas não podem ser analisadas a partir de horizontes teóricos restritivos e superficiais, sob a pena dessas análises não corresponderem nem proximamente à realidade que visam explicar.

Mas talvez seja esse o ponto pretendido dentro do debate político sobre o tema. Especificamente em relação à migração recente de sírios e africanos em direção ao continente europeu não é difícil verificar o simplismo das respostas e perspectivas adotadas. É o que nos mostra, por exemplo, Boris Johnson, que durante a campanha do Brexit $^{1}$ afirmava que a política de imigração da União Europeia acabaria jogando todos os 78 milhões de habitantes da Turquia dentro do território britânico ${ }^{2}$. Não é difícil observar a fragilidade de argumentos dessa natureza, principalmente dentro do contexto da União Europeia, que procuram definir a imigração como causa fundamental de problemas sociais mais amplos, como desemprego, déficit previdenciário, terrorismo e todas essas preocupações sociais mais presentes, que se relacionam intimamente com sobrevivência, alimentação, renda e segurança. O discurso maniqueísta entre o bem e o mal é fundamental nessa argumentação vazia e distante da realidade. Mas, os políticos normalmente não podem ser chamados de grandes pensadores, muito menos pessoas conhecidas por sua sinceridade e responsabilidade; convencer o eleitorado

1 Brexit é um acrônimo (mais corretamente um portmanteau) originado das palavras Britain e Exit, que fazem referência às discussões (e atualmente à efetiva saída) do Reino Unido da União Europeia. A inspiração da termo vem do fenômeno anterior e de mesma natureza, Grexit, que envolvia a possibilidade de saída da Grécia do bloco europeu.

2 CARLIN, John. O Ano em que Vivemos Estupidamente. El País Brasil, 03 out. 2016. Disponível em: <http://brasil.elpais.com/brasil/2016/10/03/internacional/1475498967_321999.html>. Acesso em: 03 out. 2016. 
é uma ação muitas vezes empreendida por intermédio de flexibilização da ética e da supressão dos vínculos com a plausibilidade factual.

Mas são discursos como esses, apoiados na fragilidade e medos primitivos do ser humano, que acabam conquistando seu lugar na mídia, na mente da população, nos discursos de campanha e eventualmente, acabam por se transformar em política de Estado. A amplificação de políticas de detenção administrativa de imigrantes no âmbito da União Europeia é um excepcional e profundamente preocupante exemplo de políticas simplistas e equivocadas adotadas em resposta às "necessidades" impostas pela "crise". São respostas fáceis que os governos procuram dar às hipotéticas ameaças que pairam sobre os Estados ricos receptores de migrantes pobres. Ao centralizar as ações antimigracionais dentro de âmbitos administrativos, essas respostas acaba por se constituir em um desvio, que afasta propositadamente as demandas migracionais dos organismos judiciais nacionais, que tendem a observar com mais rigor a relação entre as ações políticas e as previsões costitucionais e convencionais que protegem o ser humano e sua dignidade, principalmente quando inserido dentro de circunstâncias atentatórias a sua sobrevivência e a de sua família. Além disso, como nos mostra Fulvio Paleologo ${ }^{3}$, da Universidade de Palermo, ao determinar o tratamento dos imigrantes por intermédio de instituições e práticas administrativas, não há, via de regra, mecanismos claros de acesso ao judiciário, visto que na maioria das situações o imigrante é detido sem uma razão jurídica (não desrespeita qualquer norma e não comete qualquer crime) e sem acesso a qualquer apoio advocatício. É o limbo da burocracia, que contorna os fundamentos normativos mais basilares do ordenamento internacional e muitas vezes do constitucional, em razão de uma pretensa ação técnica e não jurídica. Já vimos isso acontecer e alegações desse tipo não são, infelizmente, novidade dentro das relações entre Estados e aqueles seres humanos qualificados como “indesejáveis". Não foi somente Eichmann que se escondia por trás de uma prática técnico-burocrática para justificar o desrespeito às garantias mais básicas dos seres humanos. Nas relações humanas e normativas as respostas fáceis originam-se dos atalhos, que repetidamete tendem a seguir os piores caminhos.

E essas políticas se aprofundam dentro de padrões perigosos de tratamento humano e de ação política. Outro exemplo atual e indubtavelmente bastante relevante são as ações de resgate e salvamento no mediterrâneo que rapidamente transformam-se em ações militarizadas, de natureza administrativa e que tendem a ultrapassar o caráter essencialmente humanitário que deveria balizar as ações nesse caso. A entrada da OTAN no início do ano de 2016 nas operações no mar

3 PAleÓlogo, Fulvio Vassallo. Detenzione Amministrativa: una storia di brutalità, violenze e violazioni. Progetto Melting Pot Europa. Disponível em: <http://www.meltingpot.org/+-Prof-Fulvio-Vassallo-Paleologo-+.html>. Acesso em: 23 set. 2016 
$\mathrm{Egeu}^{4}$, com a finalidade de resgate de imigrantes ilegais e retorno dos mesmos para a Turquia é um desses passos em atalhos administrativos que tentam obscurecer a aplicabilidade do direito internacional. $\mathrm{O}$ ato de resgatar pessoas em águas internacionais, com embarcações militares a serviço de uma organização internacional pode distorcer as responsabilidades internacionais a que normalmente os Estados estariam obrigados a respeitar. Nesse sentido, Thomas Spijkerboer, em um excepcional ensaio, questiona se nesses casos mais recentes, “estariam os membros da OTAN exercendo jurisdição? Existem objeções no direito internacional? Há meios de fugir à jurisdição e a obrigações de Direito Internacional? ${ }^{\text {" }}$ Essas não são questões fáceis de serem respondidas. Apenas a título de exemplificação, a ação da OTAN enquanto organização internacional - que, na situação em análise, tem autorização para atuar tanto em águas internacionais como em águas terrotorias (turcas, principalmente) e que é constituída por embarcações militares dos seus Estados-membro -, leva por si só um intrincado quebra-cabeças de questões que põem em relevo as complexas relações entre jurisdições nacionais e internacionais, que precisam ser definidas para que as responsabilidades individuais de Estados e Organizações Internacionais seja estabelecidas. Como coloca Spijkerboer,

Estados estão vinculados ao direito internacional quando exercem jurisdição. Se, por exemplo, uma embarcação alemã coleta pessoas quando está em águas territoriais turcas e trazem-nas para o litoral turco, estaria a Alemanha exercendo jurisdição? Esta não é uma questão irrelevante. Se a embracação alemã exerce jurisdição, a Alemanhã teria obrigações de direito internacional, relativas inter alia ao asilo ${ }^{6}$.

São questões desse tipo que surgem, e por isso a frase inicial deste ensaio indicava que a migração é um fenômeno social complexo. E, apesar de não existirem respostas fáceis, certamente existem limites claros e horizontes normativos funcionais (aos quais se tentam escapar constantemente), e todos

4 Mais informações podem ser encontradas no próprio site da organização <http://www.nato. int/cps/ en/natohq/topics_128746.htm>.

5 Tradução livre do original em Inglês: "A number of questions is relevant in order to assess the legitimacy of this in light of international law: are NATO Member States exercising jurisdiction; are there interna-tional law objections; and are there ways to evade jurisdiction and international law ob-ligations?" SPIJKERBOER, Thomas. Minimalist Reflections on Europe, Refugees and Law. European Papers, Europe, v. 1, n. 2, 2016, 545. Disponível em: <http://www. europeanpapers.eu/en/e-journal/minimalist-reflections-europe-refugees-and-law >. Acesso em 06 set. 2016.

6 Tradução livre do original em Inglês: "States are bound to international law when they exercise jurisdiction. If - for exam-ple - a German vessel picks up people while it is in Turkish territorial waters and brings them to the Turkish shore, is Germany exercising jurisdiction? This is not an irrelevant question. If such a German vessel exercises jurisdiction, Germany has a number of in-ternational law obligations, relating inter alia to asylum." SPIJKERBOER, Thomas. Minimalist Reflections on Europe, Refugees and Law. European Papers, Europe, v. 1, n. 2, 2016, 545. Disponível em: <http://www.europeanpapers.eu/en/e-journal/minimalist-reflections-europe-refugees-and-law>. Acesso em 06 set. 2016. 
eles têm como centro o ser humano, principalmente aquele tipo especial de ser humano que busca auxílio para continuar sobrevivendo, a despeito de todas as dificuldades e descaminhos da vida e da lei.

Mas, terminada essa inserção ao tema proposto para o presente trabalho, surge um questionamento, de cunho metodológico de difícil superação. Como relacionar todas essas questões acima discorridas de forma "minimalista", com o Direito Internacional Econômico? Essa não é uma identificação das mais simples, pois o fio de Ariadne que une os dois horizontes parece-nos encontrar-se muito além das meras análises empiristas sobre reflexos econômico-monetários da imigração, ou daquelas questões que, inseridas como subespécies das primeiras, analisam as decorrências de trabalho e emprego nos fenômenos de mobilização maciça entrefroteiras. Talvez, de maneira mais radicular, a relação entre os dois elementos esteja naquilo que codividem de maneira mais íntima e que os determinam, ou seja: as fronteiras (ou ausência delas).

\section{O DIREITO INTERNACIONAL ECONÔMICO - PRINCÍPIOS GENERALISTAS DE UMA HISTÓRIA DA REDEFINIÇÃO DE FRONTEIRAS}

Economia talvez nunca tenha sido uma área de conhecimento muito afeita às fronteiras. Antes mesmo dessas últimas serem artificialmente definidas, a mobilidade das sociedades humanas nômades já tinha como base o fluxo, sazonal ou físico de suas fontes de comida, energia e sobrevivência. Mais tarde, essas fontes de sobrevivência, agora munidas de valores econômicos e estratégicos, passam a se constituir como a base de contato entre povos geograficamente determinados. De forma pacífica por meio do comércio ou por intermédio da guerra, a economia - e seus blocos fundamentais de constituição: os bens e as mercadorias -, foi um dos mais poderosos mecanismos sociais que impulsionaram o contato entre os seres humanos. Por mais que as fronteiras políticas se intensificassem à medida que os povos cada vez mais se determinavam, as trocas e os interesses estratégicos em torno à ideia de economia, são a fonte de flexibilização daqueles limites políticos. Assim, desde que existem sociedades diversas e geograficamente estabelecidas, existem também elementos normativos que pautam as necessárias trocas e defesas de interesses econômicos intersociais.

Mas, dentro dessas relações sociais primitivas, e ainda por um longo período, talvez ainda não seja possível enquadrar os elementos normativos subjacentes àquele estrato fático dentro de um conceito de direito internacional econômico, pois para que esta nomenclatura tenha condições de efetivamente existir, o determinante essencial da relação normativa internacionalista, seu sujeito primordial, deverá ter surgido na história. E detentor dessa natureza especial,

7 Inspirado no trabalho de Thomas Spijkeboer. Ibid., p.533. 
o Estado-Moderno só nos é apresentado, entre o longo e criativo período que segue entre o pequeno renascimento da baixa Idade Média ${ }^{8}$ e a determinação da conformação geográfica dos Estados europeus, com a Paz de Westiphalia. O que víamos antes deste referido período histórico, talvez não pudesse ser tido como direito internacional, mas obviamente constituía-se por um discurso jurídico, pois era elemento organizacional, normativo e vinculante, que estabelecia práticas e regras obrigatórias para a condução dos processos de contato e comerciação. Mas, tanto no caso da determinação das sociedades humanas dentro de suas fronteiras, quanto no caso do direito internacional (inclusive aquele de cunho econômico), que está intimamente ligado àquela determinação espacial, estamos nos referindo, seja especificamente, seja genericamente, às fronteiras.

No caso das sociedades humanas e da sua determinação geográfica, estamos observando a construção de fronteiras que ultrapassam aquelas de origem geográfica e se instrumentalizam também a partir de elementos que se encontram além deste conteúdo espacial. Determinar sociedades humanas é um ato de diferenciar e excluir o "outro" por suas características intrínsecas, sejam elas aparentes ou criadas. Sobre isso falaremos mais adiante.

No caso do comércio e das trocas econômicas, por outro lado, temos um processo recorrente de aversão às fronteiras e de superação àquela determinação espacial. Se esta determinação, já há alguns séculos, adquire a forma de soberania, é sobre este conceito que perpassarão os longos braços da economia e de sua regulação em direção a um mundo mais dialógico e relacional. Os mecanismos de organização desse espaço não geográfico consequentemente se identificam na ideia de um ordenamento normativo contextualizado, integrador e que ultrapassa as delimitações territoriais dos Estados soberanos. Esse sempre foi a natureza e o dilema fundamental do direito internacional e principalmente de seu braço econômico-normativo. As definições basilares da disciplina são importantes neste trabalho, com o único intuito de deixar clara essa vinculação entre o âmbito normativo e as fronteiras. Assim, Mathias Herdegen ${ }^{9}$, nos explica que:

A noção "direito internacional econômico" abrange uma complexa arquitetura de normas que governam as relacões econômicas internacionais e a economia

8 Para mais informações sobre esse substancial período medieval, ao qual muitos autores, como Mario Giulliano, Paolo Grossi e Arno Dal Ri Júnior [e humildemente este que vos escreve] atribuem o nascimento do Estado Moderno, centralizado em torno do poder do Monarca, veja a importante obra: BERMAN, Harold J. Law and revolution: the formation of the western legal tradition. Massachusetts: Harvard University Press, 1983.

9 HERDEGEN, Mathias. Principles of International Economic Law. Oxford: Oxford University Press, 2013, p. 3. Tradução livre do original em ingles: "The notion 'International Economic Law' encompasses a complex architecture of rules governing international economic relations and transboundary economic conduct by States, international organizations, and private actors. The term essentially refers to the regulation of cross-border transactions in goods, services, and capital, monetary relations and the international protection of intellectual property. To some extent, it also addresses the movement of companies and natural persons as well as aspects of international competition". 
transfronteiras conduzidas por Estados, organizações internacionais e atores privados. $\mathrm{O}$ conceito refere-se essencialmente à regulação de transações transfronteiriças em bens, serviços e capitais, relações monetárias e proteção internacional de propriedade intelectual.

É inegável, a partir dessas considerações do professor alemão, que as fronteiras (e principalmente, sua transposição) são um cálculo essencial dentro $\mathrm{da}$ disciplina de direito interancional econômico. Mais do que isso, o desenvolvimento da disciplina caminha juntamente com a constante dança entre, por um lado, os aprofundamentos do horizonte interelacional e, por outro, as resistências de natureza territoriais e soberanas dos Estados em relação à essa desterritorialização produzida pela ação econômica e pela ação normativo-internacionalista. Os processos de "globalização" e "localização", que se alternam em termos de processos históricos gerais, mas que coexistem em termos de elementos materiais ( $v . g$. a diferença de intensidade entre mobilidade de capitais e mobilidade de pessoas), têm como pano de fundo as relações comerciais e econômicas. São elas que, constituindo um importante elemento estratégico político ou mesmo um importante cálculo na sobrevivência de uma sociedade, transcendem as fronteiras em direção a uma ação internacionalizada. Essa é a história de inúmeros períodos de "globalização" dentro da história humana, desde as navegações egípcias e fenícias, às construções de "impérios” regionais e mundiais - como o romano, o mongol, o cristão -, desde a Conquista da América e a colonização britânica, à constituição dos blocos econômicos regionais.

Enfim, dentro de qualquer processo global, principalmente dentro daqueles que possuem um poderoso cálculo econômico, as superação das fronteiras constitui-se como um elemento essencial, mas também determina importantes fatores de desequilíbrio e reações locais. É com esse horizonte intenso que o direito internacional econômico trabalha, tentando normatizar essa complexa relação entre, de um lado a superação daquelas linhas segmentárias e imaginárias e de outro, a manutenção de elementos "seguros" e "familiares" dos territorialismos nacionais. E talvez nada no mundo hoje converse mais com esse paradoxismo do que o processo de constituição de blocos regionais. São eles - e mais especificamente, o processo de regionalização empreendido pela Europa -, os espelhos de uma opção política que ao mesmo tempo em que sinaliza a limitação da liberdade de escolha dos Estados membros, principalmente em termos econômicos, acaba por simbolizar perfeitamente as chances, riscos e assimetrias ${ }^{10}$ de processos de globalização de velocidades variáveis. A Europa, vista como uma importantíssima resposta econômica para a superação das profundas diferenças entre Estados constantemente em guerra, e entendida hoje como exemplo de sucesso da integração econômica transfronteiriça, a "Europa Global”, também

10 HERDEGEN, Mathias. Principles of International Economic Law. Oxford: Oxford University Press, 2013, p. 19. 
tem se tornado cada vez mais referendada como a "Fortaleza Europa", fechada a fluxos transfronteiriços de pessoas, cada vez mais intensos ao mesmo tempo que são também mais concretos que os fluídos e imateriais fluxos eletrônicos de capital. Talvez na União Europeia de hoje residam elementos importantes para a análise que pretendemos, pois os temas que já definimos como fundamentais, como fronteiras, direito internacional econômico e imigração estão no cerne das questões fundantes do bloco e também em seus questionamentos contemporâneos.

\section{FRONTEIRAS, GLOBALIZAÇÃO ECONÔMICA E NOVAMENTE, FRONTEIRAS}

Certamente o mais atual processo de subversão dos limites geográficos clássicos e que tem como base prática (mas não do discurso, este muito mais profundo) sua instrumentalização por meio da economia, é a constituição do processo europeu de integração econômica. Com mais de sessenta anos percorrendo suas várias etapas de desenvolvimente a União Europeia é o grande exemplo para os tópicos de integração regional, tanto na disciplina de direito internacional público quanto em sua vertente econômica.

A concepção de Robert Schuman, de 195011 - que acuradamente reposicionou o problema das rivalidades históricas entre Alemanha e França dentro de uma perspectiva de dependência econômica forçada, tomada a partir da comunitarização das bases de desenvolvimento econômico entre os dois Estados $^{12}$-, está, atualmente, amadurecida dentro dos sistema da União Europeia, como o mais profundo sistema integracionista já vivenciado e um dos mais interessantes processos de liquefação das concepções territorialistas e ideológicas, como são as do Estado e da nacionalidade. Nesse novo contexto, a pertença a uma determinada região geograficamente delimitada não é mais garantia de que as alianças entre o indivíduo e seu reconhecimento e pertencimento a um único Estado sejam suficientes como base de sustentação de suas ações e expectativas frente aos desafios impostos pelo processo de integração. Desde as fronteiras geográficas àquelas eminentemente simbólicas, o que se observa claramente neste processo de construção de uma "federação europeia" é a perda dos referenciais territorializantes.

O que se observou nesses mais de meio século de desenvolvimento da ideia de uma Europa global e sem fronteiras, foi justamente o enfraquecimento de algumas determinações nacionais que apenas poderiam se realizar dentro de um contexto fechado, intrafronteiras. Como todo processo econômico globalizante - e a União Europeia é fruto de um intenso processo de globalização econômica -, vemos

11 SCHUMAN, Robert. Declaração de 9 de maio de 1950. Disponível em: < https://europa.eu/ european-union/about-eu/symbols/europe-day/schuman-declaration_pt>. Acesso em 06 set. 2016.

12 Ibid. 
a primazia justamente do mercado, o qual, como diria Paolo Grossi, “aparece como nunca, intolerante a limitações espaciais, tendente a uma vocação global e determinado à realizá-la ${ }^{13}$ ".

A União Europeia é fruto desse processo, ao mesmo tempo que aparece enquanto um dos leading actors no mundo globalizado de hoje. Foi a primeira a implementar um livre fluxo de pessoas, bens, serviços e capitais, com o tratado de Maastricht, já quando contava com doze Estados-membro, os quais praticamente extinguiram as fronteiras internas em benefício da fluidez e da mobilidade. E essa fluidez e mobilidade ultrapassam os largos limites da União Europeia, ao menos no que se relaciona ao livre fluxo de pessoas, com a absorção do Acordo Schengen ao quadro institucional e jurídico da União Europeia, efetuada pelo Tratado de Amsterdã ${ }^{14}$, em 1997. Logo, foi a vez das fronteiras simbólicas, como as moedas nacionais e os bancos centrais serem absorvidos pelo processo econômico europeu.

Essa esrutura de fronteiras fluídas, pelo menos naquilo que diz respeito às liberdades fundamentais da União Europeia, inegavelmente corrobora a perspectiva adotada no presente trabalho, que indica uma desterritorialização das fronteiras e principalmente das relações econômicas dentro do atual processo de globalização (dentro do qual a União Europeia é um importante exemplo). Podemos também indicar que no plano global essa desterritorialização dos processo econômicos também é planemente verificável, mas a União Europeia contém elementos que não podem ser vistos em outros lugares e que nos possibilitam analisar situações bastante peculiares. Esses elementos dizem respeito, principalmente, à efetiva diminuição dos controles transfronteiriços, também no que diz respeito ao fluxo de pessoas, e que envolve um número bastante expressivo de Estados, que de certa maneira “optaram” por dar respostas diferentes às demandas dos processos de globalização econômica. A constituição de um espaço interestatal que se organiza em torno da livre circulação é um evento relevantíssimo - tanto em termos jurídico-internacionalistas, como em termos humanos -, e que não foi ainda suficientemente explorado.

Mas não é esse o recorte que visamos observar no trabalho. Pois no que tange a esta indubtável fragilização dos controles estatais sobre suas fronteiras intraeuropeias, há por outro lado uma intensificação de outros tipos de controle, principalmente no que se refere às fronteiras exteriores do bloco econômico, que adquirem cada vez mais as feições daquelas de um Estado. Se, como afirmamos anteriormente, as determinações e reconhecimentos socais se diluem no processo de constituição do bloco econômico, outras novas determinações devem surgir em substituição às anteriores. No presente caso, algo mais amplo, algo mais genérico que as primeiras, mas mesmo assim determinações que provoquem indentificações

13 GROSSI, Paolo. Globalização, Direito, Ciência Jurídica. In: GROSSI, Paolo. O Direito entre Poder e Ordenamento. Belo Horizonte: Del Rey, 2010, p. 71.

14 Absorvido conforme determinações presentes no Anexo "B" do Tratado de Amsterdã. 
dos indivíduos com a estrutura institucional a que estão submetidos. E objetivamente esse processo passa por uma "nova" definição de fronteiras.

As determinações impostas pela Regulação 2016/1624 do Conselho e do Parlamento Europeu, que redefinem o papel dos Estados-Membro no contexto da atuação da Agência Europeia de Gestão da Cooperação Operacional nas Fronteiras Externas (FRONTEX), são um importante indicativo nesse sentido, pois transferem ainda mais prerrogativas e competências dos Estados para a União Europeia, no que tange o controle de fronteiras externas. Nestas novas regulamentações, como indicado por Philippe De Bruycker ${ }^{15}$, os Estados que não cumprirem o que determinam as políticas comuns de controle e segurança de fronteiras poderão sofrer intervenção direta do Frotex e da Comissão Europeia, conforme estatuído no art. 12 da Regulação 2016/1624.

Assim, na medida em que se verifica um longo processo de fragilização das fronteiras internas e uma facilitação dos fluxos de pessoas entre os Estados membros da organização, há um consequente importante, que é o surgimento de uma fronteira externa comum e um recrudescimento das políticas de acesso de pessoas originadas de fora do contexto europeu. Juntamente com a construção de cercas e muros de "contenção" ao estrangeiro e de endurecimento do controle de acesso ao território, a regulação do FRONTEX, que transforma o órgão em uma legítima Guarda Europeia de Fronteiras ${ }^{16}$, determinam o que agora passa a ser denominado Fortaleza Europa. Mas o que provoca a passagem do modelo da "Europa Global" para aquele da "Fronteira Europa"? A resposta é, simplesmente, a migração.

Ao falarmos em globalização não estamos apenas falando de fluxo de divisas e mercadorias, de um mundo no qual as tecnologias infotelemáticas aliadas às determinações econômicas desterritorializam as relações e aproximam as ordens Estatais "fragilizadas" 17 . A globalização também "universaliza” informações, valores, ideais de vida e meios de transporte. Se antes, os migrantes vistos como potencialmente danosos aos grandes centros econômicos tinham como limites as distâncias e as fronteiras entre os Estados, hoje, o mesmo processo de globalização permite que essas distâncias e fronteiras sejam mais próximas e mais porosas. É o dilema central no debate entre uma perspectiva econômica e jurídica e uma outra, social e humana, que nos mostra que, longe de centralizar o debate entre direito internacional econômico e imigração em termos de mobilidade econômica e de força de trabalho, ou de pressão sobre benefícios sociais e

15 DE BRUYCKER, Philippe. The European Border and Coast Guard: A new model built on an old logic. European Papers, Europe, v. 1, n. 2, 2016, p. 560. Disponível em: <http://www.europeanpapers.eu/en/e-journal/european-border-and-coast-guard-new-model-built-old-logic $>$. Acesso em 06 set. 2016.

16 Ibid., p. 562.

17 GROSSI, Paolo. Globalização, Direito, Ciência Jurídica. In: GROSSI, Paolo. O Direito entre Poder e Ordenamento. Belo Horizonte: Del Rey, 2010, p. 71. 
diminuição da arrecadação (que são potencialmente falácias, quando analisadas a partir do fenômeno migracional europeu), o debate centraliza-se efetivamente entre a crise de um processo econômico de integração e a condicionante dessa crise que é a migração em si.

A migração enquanto parte intrínseca de fenômenos de profunda transformação e desenvolvimento social ${ }^{18}$, como é de fato a globalização, acaba se relacionando com um outro fenômeno intrínseco à globalização, que são os blocos de integração regional, principalmente a União Europeia. Talvez a migração (e todo o discurso desarazoado que se produz em torno dela) seja o contraponto que coloca em xeque toda a estrutura de integração, em três pontos fundamentais: a) internamente, com a retomada de controles sobre a circulação de pessoas; b) externamente, com o endurecimento das fronteiras e; c) institucionalmente, com discussões acerca das normas da própria União Europeia e com discursos que avaliam as vantagens econômicas, sociais e políticas de pertença ao bloco como insuficientes para cobrir as desvantagens que a ameaça de imigração aparentemente oferece.

Se, como hipotetizado no presente trabalho, a constituição de blocos de integração econômica e política - como a União Europeia -, e os processos atuais de migração são decorrências intrínsecas a um mesmo fenômeno de transformação como a globalização, a relação entre eles é muito próxima. Assumimos inclusive que os dois processos dividem essa natureza pois são inseparáveis do fenômeno que os origina. Não há como falar de globalização sem que se tenha em mente processos mais ou menos intensos de compactação de fronteiras, mais ou menos intensos no que toca à mobilidade humana. E isso se afirma a todos os processos de universalização de valores, econômicos e não-econômicos, pretendidos pela humanidade até o momento. E compactação de fronteiras e mobilidade humana não são sempre necessariamente contrapostos.

Em uma outra oportunidade ${ }^{19}$, em que analisamos a relação entre o processo de conquista e colonização da América e os discursos universalizantes do direito a migrar, empreendido por Fracisco de Vitoria, verificamos que a migração dos colonizadores espanhóis para a América recém descoberta andava em um claro compasso com a universalização de valores jurídicos europeus em direção ao novo mundo. Essa universalização era necessária e possível. Necessária pois enquanto discurso racional jurídico e totalizante, incluía as populações americanas infiéis dentro do ordenamento jurídico europeu e dessa maneira fundava uma nova legitimidade jurídica no processo de conquista, puramente racional e que por isso mesmo, deixava de lado as insustentáveis fontes medievais de

18 HASS, Hein de. Migration Theory - Quo Vadis? Oxford University: International Migration Institute, p. 19. Disponível em: < https://www.imi.ox.ac.uk/pdfs/wp/wp-100-14.pdf>. Acessado em: 13 jul. 2015.

19 SUPRIMIDO COMO CONSEQUÊNCIA DA EXIGÊNCIA DE ANONIMATO. 
legitimação da conquista. Possível, pois existia dentro daquela circunstância histórica específica, uma impossibilidade material de exercício dos direitos pelos índios. A universalização do direito de migrar, estendendo-o também ao infiél, não implicaria, de fato, na instrumentalização desse direito pelos nativiamericanos, pois para eles as fronteiras que dividiam a América da Europa eram fronteiras intransponíveis. Assim, dentro daquele processo de globalização pré-moderna, migração, exploração econômica e aproximação territorial andavam no mesmo sentido, pois, via de regra, nunca há problemas em estender direitos a todos, quando apenas aqueles que criaram as regras são os que podem efetivamente exercê-las na prática.

E esse debate sobre as fronteiras é importantíssimo para nossa presente análise, pois hipotetizamos naquela mesma oportunidade que, na medida em que as fronteiras, antes isuperáveis para os infiéis americanos, tornassem-se vulneráveis e permeáveis à migração, ou seja, quando os índios pudessem efetivamente migrar em direção à Espanha, a tendência seria fortalecer outras fronteiras, geográficas ou, principalmente, psicológicas, para reestabelecer aquela intransponibilidade original, mesmo que para isso, se relativizasse os critérios jurídicos de universalidade. Nesse sentido, a globalização se dá em apenas um sentido, e quando eventualmente passa também a estender mecanismos de mobilidade humana mais efetivos a todos os envolvidos, deve-se elevar novos instrumentos de contenção a esta indesejável mobilidade.

Este é também um cenário válido para a globalização atual e neste ponto encontramos a Europa. As políticas de integração caminham bem com ideais de flexibilização de fronteiras geográficas, desde que as mesmas não possam ser efetivamente superadas por todos (apenas pelos europeus). Mas, na medida em que o processo de globalização (e integração socioeconômica) estende àqueles não-europeus pobres, mesmo que parcialmente, mecanismos mais ou menos eficientes de se superar as fronteiras europeias, novas fronteiras, internas ou externas, geográficas ou não, deverão ser erigidas.

Nesse processo, as fronteiras geográficas internas passam por um novo processo de engessamento, exclusivamente relacionado ao livre fluxo de pessoas. Mecanismos de controle de fronteiras e passaportes, que haviam basicamente deixado de ser implementados, acabam retornando como um reflexo direto dos processos migracionais, como ocorreu recentemente com Suécia e Dinamarca ${ }^{20}$. Em relação às fronteiras geográficas externas, cada vez mais políticas como o FRONTEX adquirirão autonomia frente aos Estados-membro e tornarão os procedimentos relativos à imigração mais restritos. Como mencionado no início do trabalho, esse enrigecimento da imigração acaba também por ser implemen-

20 FOLHA DE SÃO PAULO. Suécia e Dinamarca anunciam medidas de controle de Fronteiras. Disponível em: < http://m.folha.uol.com.br/mundo/2016/01/1725539-suecia-e-dinamarca-anunciam-medidas-de-controle-de-fronteiras.shtml>. Acessado em: 05 out. 2016. 
tado por meio da criminalização da migração ilegal, inclusive por mecanismos administrativos de prisão, que deliberadamente são constituídos para fugir ao controle de legalidade do poder judiciário.

Em relação às fronteiras internas, não-geográficas, podemos verificar um afastamento dos Estados do bloco em relação a políticas e posicionamentos que sejam, de alguma forma, favoráveis a um processo migracional mais legalizado. A "crise" de migração que a Europa alegadamente parece vivenciar atualmente, não abre margem ampla para que os Estados membros cumpram as suas obrigações determinadas pelos tratados de proteção ao refúgio e ao asilo dos quais são signatários, mesmo que assim o queiram fazê-lo, pois permanecem constantemente sob a ameaça de sofrerem internamente as suas fronteiras nacionais, a resistência de discursos contrários e a elevação de posições antimigracionistas perigosas, bem como sua aceitação por parte das populações nacionais, principalmente por intermédio de processos eleitorais regulares, como podemos observar, por exemplo, com o avanço preocupante de partidos como Alternative für Deutschland (AfD) na Alemanha e a Liga Nordi (LN) e Fratelli d'Italia (FdI), na Itália.

Extremamente problemáticas também, são reações que atingem a própria estrutura institucional do sistema, como a diminuição da confiança no processo de integração. Como nos mostra o gráfico abaixo ${ }^{21}$, que analisa os percentuais de respostas dos europeus acerca da imagem que eles têm da integração européia, podemos observar uma importante reversão na dinâmica das respostas a partir do período de recrudescimento da crise migracional, a partir do ano de 2015 . Se a opinião pública europeia demostrava um crescente apoio à imagem da União Europeia, a partir do estouro da crise migratória observa-se uma significativa inversão e o aumento da rejeição geral ao processo integracionista.

\section{Gráfico 1 - Imagem e Aceitabilidade Individual do Processo de Inte- gração Europeia}

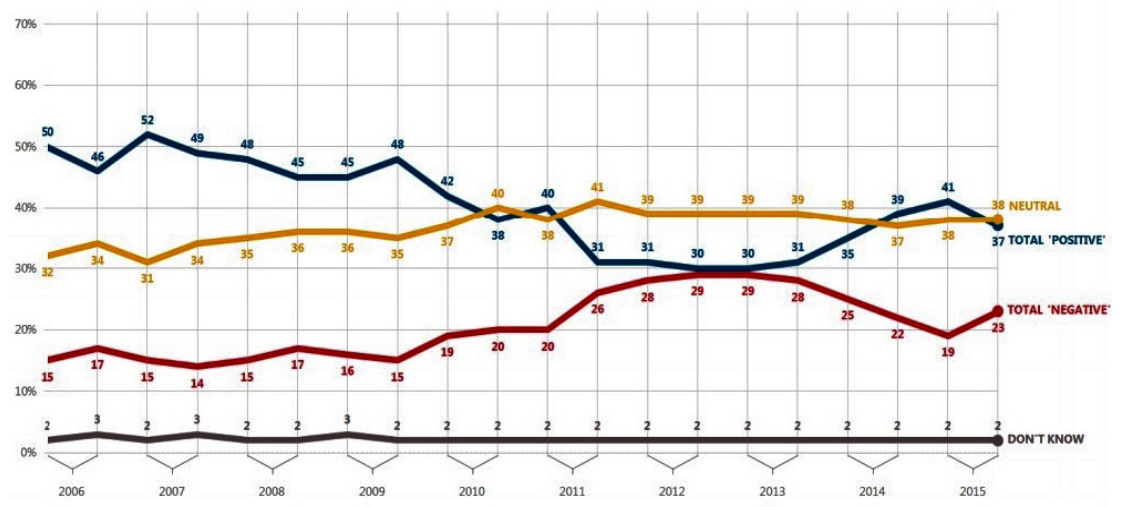

21 EUROPEAN COMISSION. Standard Eurobarometer 84: Autumm 2015. European Union, 2015, p. 6. 
Além da elevação de partidos antimigracionistas de extrema direita no contexto político europeu, a saída do Reino Unido da União Europeia é o mais poderoso indicativo desse fato e também do vínculo existente entre processos de migração e o recuo da lógica integracionista da União Europeia. Aqui reside a profunda relação entre a migração e o direito internacional econômico, na medida em que o primeiro fenômeno reúne condições suficiente para interferir de maneira profundamente negativa em uma estrutura econômica integracionista de maneira a potencializar políticas protecionistas de fechamento de fronteiras, com severos reflexos econômicos e comerciais.

E por que a migração reúne em si uma potencialidade de provocar ações tão protecionistas pelos Estados, mesmo quando se tem a sensação de que acolher pessoas em situação de extrema vulnerabilidade e miséria seja um relevante dever jurídico (e moral) a se cumprir? Aqui chegamos, enfim, à elevação das fronteiras não-geográficas externas, que são as mais restritivas e insuperáveis de todas.

Quando as fronteiras geográficas não conseguem mais conter o fluxo daquelas pessoas que são constantemente descritas como uma ameaça ao "nosso" modo de vida - pois "colocam em risco" nossos trabalhos, nossas famílias, a nossa maneira de enxergar o mundo e as relações humanas, dentre muitos outros riscos e ameaças -, fronteiras psicológicas intransponíveis começam a se fortalecer e o discurso maniqueísta fundado nas diferenças entre o "nós” e os “outros”, apesar de perigoso e insustentável, trasforma-se na base fundamental das ações políticas.

Nesse sentido, reconstrói-se a concepção generalista que define aqueles que são confiáveis. Conforme as excepcionais análises de Gallya Lahav em sua obra Immigration and Politics in the New Europe: Reinventing Borders ${ }^{22}$, a determinação do que seria o europeu segue os mesmos passos da determinação do nacional nos processos de criação de um Estado. Primeiro delimita-se o "outro", o não-pertencente, para depois identificar-se o "nós”, os pertencentes. Nos processos de integração, como indicado por Karl Deutsch $e t a l^{23}$, essa determinação entre "nós" e "os outros" passa inevitavelmente pela concretização, dentro de um território, de um senso de comunidade e de estruturas e práticas fortes o suficiente para invocar lealdades e simpatias, um sentimento de "nós” como uma verdade. O sentido de território abrange mais do que o geográfico; abrange também um espaço cultural comum, onde é possível desenvolver seu próprio ethos, com a criação de uma solidariedade, que leva a práticas de exclusão daqueles que não possuem os elementos identificadores. Um povo, inclusive o povo europeu, é

22 LAHAV, Gallya. Immigration and Politics in the New Europe: Reinventing Borders. Cambridge: Cambridge Univesity Press, 2004.

23 DEUTSCH, Karl; BURRELl, S. A.; KANN, R. A.; LEE, M.; LICHTERMAN, M.; LINDGREN, R. E.; LOEWENHEIM, F. L.; VAN WAGENEN, R. W. Political Community and the North Atlantic Area: International Organization in the Light of Historical Experience, Princeton: Princeton University Press, 1957 
então um grupo social vivendo em determinado espaço e possuidor de traços característicos que definem normas e práticas culturais comuns, que caracterizam-se por signos linguísticos e etnográficos distintos (de outros, do "outro") e que são "naturais" a pessoas como "nós”, por conta de uma alegada ancestralidade desta identificação.

Então, quem é esse europeu que se identifica acima das determinação nacionais? Como esta identificação é construída? As respostas a essas perguntas estão menos relacionadas com a construção do mercado ou com as condições da integração e muito mais com as distinções culturais e religiosas. A Integração europeia facilita-se, principalmente, pelo conteúdo cultural tradicional e "comum" - o religioso (cristandade). É este elemento que serve de base intrínseca para demarcar os insiders dos outsiders. Como indicam os comentários de um membro do parlamento europeu, destacado da obra de Lahav:

Nós precisamos fazer que os judeus fizeram em Israel, quando eles declararam que qualquer judeu que se apresentasse na fronteira de Israel teria o direito de entrar, quaisquer que fossem suas motivações. E eu pessoalmente acho que todo Europeu que venha de outro país da Europa tem o mesmo direito que um Judeu em Israel. Ele é o europeu para a Europa. Esse é o limite para mim. Extraeuropeus, não; intraeuropeus, sim $^{24}$.

Estas são as fronteiras elevadas frente a novo processo de migração, que são intransponíveis para o imigrante pois contrapõem-se objetivamente em relação ao que ele é, enquanto pessoa, enquanto ser humano. Quando as fronteiras geográficas se comprimem e se enfraquecem, essas são as fronteiras psicológicas que são construídas. E obviamente, em situações de instabilidade política ou econômica, surgem as respostas fáceis que identificam os inimigos. E abrir as fronteiras para essas pessoas, ou respeitar o que estabelece a lei interna ou os tratados internacionais acaba sendo uma traição, punida com a perda do controle político do Estado em benefício de partidos e discursos oportunistas e, mais severamente em termos integracionistas, punidos com o afastamento dos Estados membros desses ideais econômicos e políticos que até o momento pautaram a construção da União Europeia. Esse é o caso do Reino Unido e de outros potenciais Estados.

Enfim, aqui está a determinação da relação profunda entre migração e direito internacional econômico, vista sob os olhos do processo de integração da União Europeia. Por mais que a mobilidade humana seja um dos resultados de um processo de globalização econômica - como também o são a ordenação do sistema financeiro internacional e as regras de direito internacional econômico -, a migração talvez seja um dos elementos mais poderosos na estruturação de políticas protecionistas e contrárias a discursos integracionistas. É o que nos

24 LAHAV, Gallya. Immigration and Politics in the New Europe: Reinventing Borders. Cambridge: Cambridge Univesity Press, 2004, p.160. 
mostra a "crise" humanitária que bate às portas da Europa, hoje, e é o que nos mostra outros tantos discursos políticos de ocasião.

\section{CONSIDERAÇÕES FINAIS}

As análises dos estreitos vínculos entre direito internacional econômico e migração acabam observando, grosso modo, as relações de cunho puramente econômico, localizadas dentro das relações de trabalho, ou das consequências transfronteiriças em termos de investimentos, remessas de divisas, dentre outros. Essa é uma análise que compartilha uma sistemática de causa e efeito, que muitas vezes não podem ser observadas na prática, conforme determina a teoria ou, mais comumente, o discurso político. É muito improvável, dentro de um horizonte científico de análise de dados, que se possa comprovar, ao menos na Europa, nexos causais entre o aumento da imigração e o aprofundamento da crise econômica europeia, seja esta última determinada com base no aumento do desemprego ou na crise social dos Estado e na consequente diminuição dos benefícios sociais dos Estados europeus.

O número de imigrantes que chegam à Europa, frente à riqueza produzida no continente, ao expressivo número de habitantes e à capacidade de absorção de indivíduos em sua economia, parece não representar um grande perigo matemático ou jurídico. A Europa tem condições de bancar essa responsabilização, sem desrespeitar suas obrigações convencionais estabelecidas pelo direito internacional. Esse talvez não seja o caso de Estados como a Jordânia ou o Líbano, que indiscutivelmente enfrentam uma profunda crise econômica e humanitária por conta da expressiva proporção de imigrantes miseráveis que procuram abrigo em suas fronteiras.

A relevância dessas questões e o debate profundo que implicam - contrariamente do que tenta afirmar o senso comum político e econômico -, podem ser adequadamente observados em pesquisas expressivas ${ }^{25}$ produzidas atualmente. $\mathrm{O}$ que nos interessa, neste trabalho, é demostrar, mesmo que minimalisticamente, que a relação entre processos de migração e direito internacional econômico - aqui analisado a partir de um de seus objetos, os processos de integração regional, e mais especificamente, a União Europeia -, divide um patamar mais elevado. São ambos, processos originados das mesmas alterações sociais profundas vivenciadas por grande parcela da humanidade hoje e que podem, grosso modo, ser

25 Veja, por exemplo: HASS, Hein de. Migration Theory - Quo Vadis? Oxford University: International Migration Institute. HASS, Hein de. Mobility and Human Development. Oxford University: International Migration Institute. ABDELMALEK, Sayad. A Imigração ou os Paradoxos da Alteridade. São Paulo: Editora Universidade de São Paulo, 1998. CORNELISSE, Galina. Immigration Detention and Human Rights: Rethinking Territorial Sovereignty. Leiden: Martinus Nijhoff, 2010. RIZELO, Ana Flávia Sabi. A dicotomia entre o Instituto do Refúgio e as políticas de cooperação internacional: uma análise da ação internacional no caso dos refugiados sírios no Líbano. Florianópolis: Faculdade Cesusc, Monografia, 2015. 
identificados com a "globalização". Globalização econômica, mas também do conflito, da miséria, dos nacionalismos e das reações localizantes do terrorismo.

E, por dividirem o mesmo processo de alteração profunda da sociedade, acabam também, respondendo conjuntamente, aos desafios impostos por esses novos paradigmas. A migração não cria a crise dos processos de integração econômica, apenas serve de discurso para que movimentos localizantes e atomizantes dos próprios Estados membros ganhem projeção e aceitação social. É com o medo do imigrante que se elevam novas barreiras, intransponíveis, e que acabam circunscrevendo elementos de cooperação, integração e fluxo livre entre fronteiras, em circulos cada vez menores e mais suspeitosos de protecionismo e xenofobia.

Migração e Integração são fenômenos originados do mesmo processo de globalização e um não existe sem o outro. Lutar contra a migração é lutar contra a integração e consequentemente contra o direito internacional econômico e principalmente, contra um processo de globalização profundo que está reposicionando, para o bem ou para o mal, as sociedades humanas. Nessa luta, infelizmente, apenas o retorno de um mundo protecionista em que os Estados decidem unilateralmente seus interesses, aparece no horizonte. Já passamos por isso, muitas vezes, e em nenhuma delas as consequências foram agradáveis.

\section{REFERÊNCIAS}

CARLIN, John. O Ano em que Vivemos Estupidamente. El País Brasil, 03 out. 2016. Disponível em: <http://brasil.elpais.com/brasil/2016/10/ 03/ internacional/1475498967_321999. html>. Acesso em: 03 out. 2016.

DE BRUYCKER, Philippe. The European Border and Coast Guard: A new model built on an old logic. European Papers, Europe, v. 1, n. 2, 2016, p. 559-569. Disponível em: <http://www.europeanpapers.eu/en/e-journal/european-borderand-coast-guard-new-model-built-old-logic>. Acesso em 06 set. 2016.

DEUTSCH, Karl; BURRELl, S. A.; KANN, R. A.; LEE, M.; LICHTERMAN, M.;

LINDGREN, R. E.; LOEWENHEIM, F. L.; VAN WAGENEN, R. W. Political Community and the North Atlantic Area: International Organization in the Light of Historical Experience, Princeton: Princeton University Press, 1957

EUROPEAN COMISSION. Standard Eurobarometer 84: Autumm 2015. European Union, 2015, p. 6.

FOLHA DE SÃO PAULO.. Suécia e Dinamarca anunciam medidas de controle de Fronteiras Disponível em: < http://m.folha.uol.com.br/mundo /2016/01/1725539-suecia-e-dinamarca-anunciam-medidas-de-controle-defronteiras.shtml>. Acessado em: 05 out. 2016.

GROSSI, Paolo. Globalização, Direito, Ciência Jurídica. In: GROSSI, Paolo. O Direito entre Poder e Ordenamento. Belo Horizonte: Del Rey, 2010. 
HASS, Hein de. Migration Theory - Quo Vadis? Oxford University: International Migration Institute. Disponível em: < https:/www.imi.ox.ac.uk/pdfs/wp/wp-10014.pdf $>$. Acessado em: 13 jul. 2015.

HERDEGEN, Mathias. Principles of International Economic Law. Oxford: Oxford University Press, 2013.

LAHAV, Gallya. Immigration and Politics in the New Europe: Reinventing Borders. Cambridge: Cambridge Univesity Press, 2004.

PALEÓlOGO, Fulvio Vassallo. Detenzione Amministrativa: una storia di brutalità, violenze e violazioni. Progetto Melting Pot Europa. Disponível em: <http://www.meltingpot.org/+-Prof-Fulvio-Vassallo-Paleologo-+.html>. Acesso em: 23 set. 2016

SCHUMAN, Robert. Declaração de 9 de maio de 1950. Disponível em: < https:// europa.eu/european-union/about-eu/symbols/europe-day/schuman-declaration_ pt>. Acesso em 06 set. 2016.

SPIJKERBOER, Thomas. Minimalist Reflections on Europe, Refugees and Law. European Papers, Europe, v. 1, n. 2, 2016, p. 533-558. Disponível em: <http:// www.europeanpapers.eu/en/e-journal/minimalist-reflections-europe-refugeesand-law>. Acesso em 06 set. 2016.

VELOSO, Paulo Potiara de Alcântara. Migration, Law Innovation and the Infidel world: the instrumental face of European civilizing presumptions under the universalized ius gentium of Francisco de Vitoria. $4^{\mathrm{TH}}$ Biennial ESCLH Conference. Gdansk, 2016.

Recebido em: 08/08/2018.

Aprovado em: 30/11/2018. 


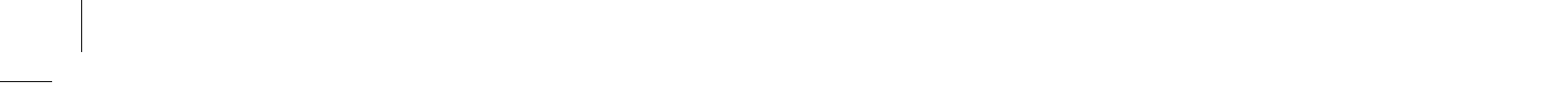

